\title{
Health and Functional Outcomes for Shared and Unique Variances of Interpersonal Callousness and Low Prosocial Behavior
}

\author{
Alan J. Meehan ${ }^{1}$ (D) Barbara Maughan ${ }^{1} \cdot$ Edward D. Barker ${ }^{2}$ \\ Published online: 1 August 2019 \\ (C) The Author(s) 2019
}

\begin{abstract}
Previous factor-analytic studies identify significant comorbidity between interpersonal-callous (IC) traits and low prosocial behavior (LPB), which, in turn, is associated with high levels of childhood risk exposure and psychopathology. Longitudinal associations between IC, LPB, or their combination, and early-adult health and social functioning have not been investigated, however. Extending a previously-identified bifactor model within a prospective birth cohort, this study applied latent path analysis to test direct and indirect pathways (via adolescent delinquency, substance use, and physical activity) between these general and specific factors (age 13) and (i) emotional problems (age 18), (ii) physical health problems (age 18), and (iii) classification as 'not in education, employment, or training' (NEET; age 20). All models controlled for childhood adversity and IQ. Bifactor-specific estimates indicated that the residual IC factor did not reliably denote unique variance over and above a general factor (IC/LPB). IC/LPB itself was directly associated with NEET classification, while the residual LPB factor was associated with better emotional and physical health. IC/LPB also indirectly associated with emotional problems via greater adolescent delinquency, and with physical health problems via lower physical activity. In contrast, residual LPB variance was either non-significantly or negatively related to these adolescent domains. Findings indicate that the shared variance underlying IC and LPB confers an increased risk for poor health and functional outcomes in emerging adulthood, and highlight delinquency and physical inactivity as potential adolescent treatment targets that may mitigate the risk for health difficulties at high levels of this IC/LPB construct.
\end{abstract}

Keywords Interpersonal callousness $\cdot$ Low prosocial behavior $\cdot$ Child psychopathy $\cdot$ Psychopathology $\cdot$ Avon Longitudinal Study of Parents and Children (ALSPAC)

The presence of psychopathic traits in childhood and adolescence, particularly its interpersonal (i.e., grandiose, manipulative) and affective features (i.e., low empathy/guilt) consistently characterizes youth with more severe, chronic, and diverse

Electronic supplementary material The online version of this article (https://doi.org/10.1007/s10862-019-09756-9) contains supplementary material, which is available to authorized users.

Alan J. Meehan

alan.meehan@kcl.ac.uk

Edward D. Barker

ted.barker@kcl.ac.uk

1 Social, Genetic \& Developmental Psychiatry Centre, Institute of Psychiatry, Psychology \& Neuroscience, King's College London, 16 De Crespigny Park, London SE5 8AF, UK

2 Department of Psychology, Institute of Psychiatry, Psychology \& Neuroscience, King's College London, 16 De Crespigny Park, London SE5 8AF, UK conduct problems (CP; for review, see Frick et al. 2014). This 'interpersonal-affective' dimension, commonly referred to as 'interpersonal callousness' (IC) in the child and adolescent literature (e.g., Byrd et al. 2012; Byrd et al. 2018; Pardini et al. 2006), aligns with Factor 1 of the Psychopathy Checklist (PCL; Harpur et al. 1989), the prototypical measure of the construct. Of particular note, longitudinal studies have linked IC with poor early-adult developmental outcomes, including delinquency and antisocial personality features (Forsman et al. 2010; McMahon et al. 2010; Pardini and Loeber 2008), criminal arrests and charges (Kahn et al. 2013; Lynam et al. 2009), and both violent and general recidivism (Salekin 2008), even after controlling for a range of delinquency-related risk factors. Indeed, the utility of these traits in distinguishing a high-risk subgroup of young people is reflected in the DSM-5's 'limited prosocial emotions' specifier for conduct disorder diagnosis (American Psychiatric Association 2013).

Elsewhere, childhood studies consistently report a moderate association between higher levels of psychopathic traits 
and lower levels of prosocial behavior (e.g., caring, comforting, or volunteering behaviors; see Eisenberg et al. 2006), with these youth characterized by higher levels of early risk exposure and co-occurring externalizing and internalizing problems (Barker et al. 2011; Meehan et al. 2017). In an exploratory factor analysis of childhood behavioral measures, Dadds et al. (2005) identified a single factor comprised of 'Callous-Unemotional' (i.e., PCL Factor 1) items from the Antisocial Process Screening Device (APSD; Frick and Hare 2001; e.g., 'no guilt', 'does not show feelings or emotions', 'breaks promises') and reverse-coded 'prosocial' items from the Strengths and Difficulties Questionnaire (SDQ; Goodman 1997; e.g., 'unhelpful if someone is hurt, upset, or ill', 'not kind to younger children'). This combination of 'callous' and 'low prosocial' items has since been utilized extensively in youth studies of psychopathic traits (e.g., Dadds et al. 2006; Fontaine et al. 2011; Hawes et al. 2014; Viding et al. 2005). A recent attempt to clarify the relative shared and unique variance underlying IC and 'low prosocial behavior' (LPB) items within an epidemiological cohort found that a bifactor model provided the best fit for the two constructs (Meehan et al. 2019). Here, a general factor (termed 'IC/LPB') was associated with the highest levels of childhood risk exposure and psychiatric comorbidity. Additionally, based on recommended fit indices for bifactor models (see Rodriguez et al. 2016a, b), the residual factor for IC items did not appear to capture meaningful distinct variance over and above this general factor. However, an equivalent residual factor for LPB items, which here was associated with lower levels of parental warmth and higher levels of social-cognitive impairment, appeared to reflect some degree of unique variance. The emergence of a reliable 'callous-low prosocial' factor from these analyses may indicate conceptual overlap between the two constructs, such that a self-centered lack of consideration or concern for others may be a key feature of a callous interpersonal style.

While the combination of IC and LPB appears to index a more severe profile of early risk, little is known about how their co-occurrence may influence adjustment into adulthood. As outlined above, most research on youth callousness has focused on delinquency, with scant examination of wider health or functional outcomes. On the other hand, low prosocial behavior, as well as being associated with externalizing behaviors (Flynn et al. 2015; Nantel-Vivier et al. 2014), has also been linked to poor socio-emotional adjustment, including academic underachievement (Caprara et al. 2000; Gerbino et al. 2017). Of note, persistently high levels of CP predict greater mental and physical health difficulties in adulthood, along with worse education and employment outcomes (Fergusson et al. 2005; Moffitt et al. 2002; Odgers et al. 2007). In particular, young adults 'not in education, employment, or training' (NEET), a classification associated with chronic unemployment and poor physical and mental health (Franzén and Kassman 2005), are more likely to report histories of delinquency, substance abuse, and mental health problems (Rodwell et al. 2017; Veldman et al. 2015). Given that IC and LPB both designate early-onset and persistent CP, their shared variance (i.e., IC/LPB) may, in turn, be associated with adverse adult health and adjustment, whether directly or by initiating indirect developmental pathways via delinquency or related 'health-compromising' behaviors (e.g., substance use), which themselves increase the risk for a variety of negative health and behavioral outcomes (van Nieuwenhuijzen et al. 2009; Weinberg et al. 1998). At the same time, certain behaviors may confer promotive or protective effects against adverse early-adult outcomes. For example, physical activity is consistently associated with better health, emotional well-being, and academic achievement (Ahn and Fedewa 2011; Reiner et al. 2013; Spruit et al. 2016), while inactivity has been linked with delinquency (Morris and Johnson 2014).

It is also possible that any developmental pathways identified during adolescence may not be the result of IC/LPB per se, but instead reflect wider developmental vulnerability due to adverse early-life social contexts. Early-life adversity is prospectively associated with IC and LPB (Barker et al. 2011; Flouri and Sarmadi 2016), as well as delinquency, substance use, psychopathology, physical inactivity, and adverse health and socio-economic outcomes (Currie and Widom 2010; Dube et al. 2003; Felitti et al. 1998; Raposa et al. 2014; Taylor et al. 2011). In addition, cognitive deficits (i.e., low IQ) may also account for later health and adjustment problems: low IQ is predictive of an increased risk of unemployment at age 21 years (Caspi et al. 1998), while higher adolescent IQ has been linked with better health at age 40 based on self-reports and medical diagnoses (Der et al. 2009). Therefore, any proposed developmental models should adequately control for these potential confounding factors.

Consequently, the current study sought to extend a previous bifactor model (Meehan et al. 2019) to test prospective associations between these latent factors and early-adult measures of emotional well-being, physical health, and NEET status. Specifically, using three latent path models spanning from early adolescence to emerging adulthood, we aimed to examine direct effects between the relative shared and unique variances underlying IC and LPB and later health and social outcomes, over and above the effects of prior childhood adversity and intelligence, and test whether these constructs were indirectly related to early-adult outcomes via adolescent delinquency, substance use, and/or physical activity.

\section{Method}

\section{Participants}

Data were drawn from the Avon Longitudinal Study of Parents and Children (ALSPAC), a population-representative 
British birth cohort established to understand how genetic and environmental characteristics influence health and development in parents and children (Boyd et al. 2013; Fraser et al. 2013). Pregnant women resident in the former Avon Health Authority with expected delivery dates between 1 April 1991 and 31 December 1992 were eligible for recruitment, resulting in a cohort of 14,541 pregnancies, with 13,988 singletons/ twins alive at 12 months. Ethical approval was obtained from the ALSPAC Ethics and Law Committee, as well as various Local Research Ethics Committees. Please note that the study website contains details of all the data that is available, through a fully searchable data dictionary: http://www.bris. ac.uk/alspac/researchers/data-access/data-dictionary/.

Participants with complete data at ages 18 or 20 ranged from 2,534-3,077, depending on the outcome measure. Within the smallest of these analytic samples, $62.9 \%$ of participants were female, compared to $49.7 \%$ at initial enrolment. It should be noted that this sample was $96.6 \%$ White; however, this is consistent with initial enrolment (96.1\%; Boyd et al. 2013). In terms of socio-economic status (SES), 6.3\% of mothers were classified as 'low SES', based on classes IV and V of the UK Registrar General's social class scale (Office of Population Censuses and Surveys 1991), compared to $12 \%$ of the initial sample. To formally examine the impact of attrition, we used multivariate logistic regression with odds ratios (ORs) to test whether being male (OR $=2.12,95 \%$ CIs $=1.92-2.34)$, low SES $(\mathrm{OR}=1.54,95 \% \mathrm{CIs}=1.28$ $1.84)$, early parenthood $(<19$ years; $\mathrm{OR}=2.02,95 \% \mathrm{CIs}=$ 1.70-2.40), or low maternal educational attainment (basic school-leaving/vocational qualifications only; $\mathrm{OR}=2.11$, 95\% CIs $=1.84-2.43$ ) predicted exclusion from our smallest analytic sample $(n=2,534)$. All four variables were significantly associated with exclusion. However, previous analyses of bias in ALSPAC highlight that, although attrition impacted the prevalence of psychiatric disorders, associations between risks and outcomes generally remain intact, such that observed associations are likely to be conservative of true population effects (Wolke et al. 2009).

\section{Measures}

Interpersonal Callousness A six-item measure was completed by mothers when their child was 13 years old (Moran et al. 2008). Using a five-point scale ( $0=$ 'not at all' to $4=$ 'always'), items rated the frequency that the child: (i) 'makes a good impression at first, which people tend to see through after getting know him/her'; (ii) 'has shallow or fast-changing emotions'; (iii) 'is usually genuinely sorry if $\mathrm{s} / \mathrm{he}$ has hurt someone or acted badly' (reversed); (iv) 'can seem cold-blooded or callous'; (v) 'keeps promises' (reversed); and (vi) 'is genuine in his/her expression of emotions' (reversed). Initial item selection was informed by factor analyses of scales measuring Factor 1 of the PCL-R (i.e., interpersonal-affective characteristics), the international standard for the assessment of psychopathy that has played a dominant role in the establishment of childhood measures (Frick et al. 2000; Frick et al. 1994). Validating these items among 182 clinic-referred or school-recruited children scoring highly for externalizing disorders, Moran et al. (2009) found a high correlation $(\mathrm{r}=.81)$ with the APSD's (Frick and Hare 2001) Callous-Unemotional subscale. Internal consistency was acceptable within the current sample $(\alpha=.75)$.

Low Prosocial Behavior The prosocial subscale of the Strengths and Difficulties Questionnaire (SDQ; Goodman 1997), a widely-used screening instrument with established reliability and validity, was completed by mothers when the child was aged 13. Five items assessed behavior 'in the past six months' along a three-point scale $(0=$ 'not true' to $2=$ 'certainly true'): (i) 'considerate of other's feelings'; (ii) 'shares readily with other children'; (iii) 'helpful if someone is hurt, upset, or ill'; (iv) 'kind to younger children'; and (v) 'volunteers to help others'. Responses were reversed, such that higher scores captured lower prosociality. Internal consistency was acceptable $(\alpha=.71)$.

Delinquency Adolescent delinquency was measured using self-report items from the Edinburgh Study of Youth Transitions in Crime (Smith and McVie 2003) at ages 13 (15 items), 15 (16 items), 17 (17 items) and 18 years (12 items). Original response scales were dichotomized $(0=$ 'no'; 1 = 'yes') based on whether respondents had partaken in a given activity in the past year (e.g., stole something from a shop, damaged property, broke into a house or building, been rowdy or rude in public place; see Table S1 for complete items at each time-point). Items were summed to create a total count of delinquent behaviors. Internal consistency was acceptable at all ages $(\alpha=.66-.82)$.

Substance Use Self-reported tobacco and cannabis use was measured at ages 14,16 , and 18 years, using frequency items $(0=$ 'never' to $6=$ 'daily' $)$. Alcohol consumption and alcoholrelated behaviors (also self-reported) were assessed at ages 16 and 18 years via the Alcohol Use Disorders Identification Test (AUDIT; Saunders et al. 1993), a 10-item screening tool developed by the World Health Organization. AUDIT items showed good internal reliability at ages $16(\alpha=.77)$ and 18 years $(\alpha=.75)$.

Physical Activity Self-reported physical activity was assessed at ages 13,16 , and 18 years by asking 'During the past year, how often did you do any exercise (going to the gym, brisk walking, or sports activity)?' (range: $0=$ 'never' to $4=$ ' 5 or more times a week').

Emotional and Physical Health Problems Health outcomes at age 18 years were drawn from the 36-item Short Form 
Health Survey (SF-36; Ware and Sherbourne 1992). Emotional problems were represented by a latent factor derived from Mental Health (5 items; $\alpha=.80$ ) and Role Emotional ( 3 items; $\alpha=.92$ ) subscales. These captured the frequency of emotional problems in the past month (e.g., 'been very nervous', 'felt downhearted or low'), and the burden of these problems on respondents' everyday activities, respectively (e.g., 'cut down on time spent on work or other activities', 'accomplished less than they would like'). Items were measured on a five-point scale ( 0 $=$ 'none of the time' to $4=$ 'all of the time').

A latent factor for physical health problems was derived from two subscales. First, nine items from the Physical Functioning subscale $(\alpha=.92)$ assessed the degree to which the respondent was physically limited in completing a range of activities (e.g., 'lifting or carrying groceries', 'climbing several flights of stairs', 'walking one hundred meters' etc.), rated from 0 ('not limited') to 2 ('limited a lot'). Second, the Role Physical subscale (4 items; $\alpha=.92$ ) captured the impact of respondents' physical limitations on everyday activity in the past month (e.g., 'limited in work or other activities', 'had difficulty performing work or other activities [i.e., involved extra effort]'), rated from 0 ('none of the time') to 4 ('all the time').

'Not in Education, Employment, or Training' (NEET) At age 20, as part of a wider questionnaire on education and employment, respondents were asked whether they were 'currently in employment or doing any education or training'. The dichotomous response set was used to compare young people 'not in education, employment, or training' (NEET; coded 1) to the remainder of the sample (coded 0 ). This measure therefore identifies young people not at school or work, for whatever reason.

Early-Life Adversity Indicators of family, parental, and sociodemographic risk were collated under the short form of the Family Adversity Index (FAI; Bowen et al. 2005). This captured 15 family-based risk factors, including maternal age, educational qualifications, housing adequacy, financial difficulties, and maternal psychopathology, substance abuse, and crime. An item was rated 1 if adversity was present, with scores summed to create a scale. Totals for two postnatal periods (birth to age 2, and age 2-4 years) were combined to create a cumulative early-life adversity score (range 0-20).

Intelligence A short form of the Wechsler Intelligence Scale for Children, Third Edition (WISC-III; Wechsler et al. 1992) was administered at age 8 years. This comprises ten subtests of verbal and performance intelligence. The age-adjusted fullscale IQ score, representing the sum of all subtests, was utilized here.

\section{Statistical Analyses}

We estimated separate latent path models for each outcome, using Mplus v7.11 (Muthén and Muthén 2012): (i) emotional problems (Model A); (ii) physical health problems (Model B); and (iii) NEET status (Model C). For each model, only those with complete data for the outcome were included in analysis, with all models controlling for childhood adversity and IQ. With the exception of the binary NEET outcome, latent factors were estimated for each intermediary (adolescent delinquency, substance use, physical activity) and outcome domain (emotional problems, physical health problems) to maximize shared variance between indicators and minimize inclusion of error variance (Skrondal and Rabe-Hesketh 2004). The underlying latent factor structures for each model are presented in Figs. S1-S3.

At age 13, we replicated (Meehan et al.'s 2019) bifactor model, specifying a general factor (IC/LPB) for shared variance among all items and specific IC and LPB factors for residual covariance among item subsets, with all covariance between factors fixed to zero (Brown 2006). Recent work has raised concerns around the propensity of bifactor models to unwittingly capture measurement error or 'noise' variance, rather than theoretically-distinct constructs, such that associations with external variables were likely to be unreliable (Bonifay et al. 2017; Rodriguez et al. 2016b). To address this issue, we derived a series of bifactor-specific fit indices using the Omega program (Watkins 2013) to assess the reliability and construct validity of estimated factors. These indices and their interpretation are summarized below; for comprehensive accounts of their calculation, see Rodriguez et al. (2016a, b).

First, coefficients omega hierarchical $\left(\omega_{H}\right)$ and hierarchical subscale $\left(\omega_{H S}\right)$ were used as model-based reliability estimates, analogous to coefficient alpha. Specifically, $\omega_{H}$ measures the proportion of systematic variance in the unit-weighted total score attributable to individual differences on the general factor, while $\omega_{H S}$ assesses the proportion of subscale score variance accounted for by individual differences on its intended specific factor after controlling for variance explained by the general factor. Although $\omega_{H}$ or $\omega_{H S}$ values closer to $>.75$ are preferred, there are no absolute standards, and values $>.50$ can indicate sufficient reliability (Reise et al. 2013). Second, construct reliability, or the extent to which a latent factor is represented by its underlying items, was measured using $H$, where a value of .70 indicates adequate representation, such that the factor is likely to replicate well across samples. Finally, explained common variance (ECV) and percentage of uncontaminated correlations (PUC) were used to assess the relative multidimensionality of the bifactor model. ECV is the proportion of variance explained by all factors that is accounted for by the general factor, while PUC indicates the proportion of correlations between items that are influenced by the general factor. Where both ECV and PUC are $>.70$, the 
data may be thought of as essentially unidimensional, to the extent that estimating a single latent factor may be more parsimonious than the bifactor structure (Rodriguez et al. 2016a).

For Models A and B, maximum likelihood estimation with robust standard errors (MLR) was used to correct for possible non-normal distribution of study variables. As the NEET outcome was binary, robust weighted least squares (WLSMV) estimation was used for Model C. In all models, full information maximum likelihood (FIML) was used to account for missing data. Model fit was evaluated using the comparative fit index (CFI) and Tucker-Lewis index (TLI), where values $\geq .90$ and $\geq .95$ represent acceptable and good fit, respectively (Hu and Bentler 1999), and the root mean square error of approximation (RMSEA), where values $\leq .08$ and $\leq .05$ suggest adequate and close fit, respectively (Browne and Cudeck 1993). These thresholds were originally derived for continuous data (i.e., Models A and B). However, evaluating fit indices in models with binary outcomes using WLSMV (i.e., Model C), Yu (2002) found these cut-off values to be broadly applicable where $N \geq 250$.

We inspected developmental pathways in two steps:

- Step 1: Direct effects. For each model, we estimated the following direct effects: (i) IC/LPB, IC, and LPB $\rightarrow$ earlyadult outcome (emotional problems, physical health problems, or NEET status); (ii) IC/LPB, IC, and LPB $\rightarrow$ delinquency, substance use, and physical activity; and (iii) delinquency, substance use, and physical activity $\rightarrow$ earlyadult outcome.

- Step 2: Mediation and indirect effects. Indirect effects were tested using the 'model indirect' Mplus command and bootstrapped 10,000 times with bias-corrected 95\% confidence intervals to account for non-normality in standard errors. We distinguish between mediation and indirect effects here. Mediation is contingent on a significant direct effect between predictor and outcome (or c-path) being explained by an intervening variable (Preacher et al. 2007). This is represented as the product of the pathways from predictor $\rightarrow$ mediator ( $a$-path) and mediator $\rightarrow$ outcome ( $b$-path), or the $a b$ pathway. In contrast, indirect effects, though calculated in the same way, do not require a significant direct effect (i.e., $c$-path) to be present (Mathieu and Taylor 2006). Effect sizes for indirect pathways were represented by $P_{M}$, or the ratio of indirect effect to total effect, as recommended by Wen and Fan (2015) for multiple-mediation models with large samples $(N>500)$.

\section{Results}

First, before proceeding with item-level analysis, the correlation $(r=.49)$ between manifest (i.e., summed) IC and LPB scores was noted, suggesting that they represented moderately related, but nonetheless distinct, domains. Standardized pathways for the three path models, hereafter referred to as Model A (emotional problems; $n=2,541$ ), Model B (physical health problems; $n=2,534$ ), and Model C (NEET status; $n=3,077$ ), are presented in Fig. 1a-c. All three models fit the data adequately (see Table 1), and latent structures were consistent across all three models (for item loadings among latent factors, see Figs. S1-S3). Bivariate correlations between latent factors within each model can be found in Tables S2-S4.

Additional fit indices for each of the three bifactor measurement models (see Table 2) revealed that, similar to previous findings in this cohort (Meehan et al. 2019), the specific IC factor (i.e., residual variance for IC items having accounted for variance shared with LPB) showed relatively poor reliability. $\omega_{H S}$ statistics across the three models suggested that this factor only accounted for $4.9-11.5 \%$ of the variance in the proposed IC subscale score, having partitioned out variance explained by the general factor. In addition, the latent factor appeared to be a poor representation of the IC items themselves $(H=.25-.28)$. Given its apparent unreliability, we did not specify longitudinal associations between the latent IC factor and adolescent or early-adult latent factors within the three models.

Elsewhere, high $\omega_{H}$ values for the general factor (i.e., IC/ LPB) indicated that the majority (68.4-71.6\%) of total score variance was accounted for by individual differences on this latent factor, while $H$ values (.81-.83) indicated a factor that was well-defined by the 11 items. At the same time, across the three models, there was no instance where both ECV and PUC values exceeded .70 . This suggested that although the IC/LPB factor explained the majority of variance among these items, a non-trivial amount of variance was explained by the specific factors (Rodriguez et al. 2016a). Of note here, although neither $\omega_{H S}(.35-.38)$ or $H$ values (.52-.53) for the residual LPB factor reached accepted thresholds, this latent factor showed better overall reliability in all three models compared to the residual IC factor. Therefore, in an effort to capture some of the multidimensionality suggested by the sub-optimal combination of ECV and PUC values, we specified associations between this factor and other latent domains in each model. These associations are described in subsequent sections; however, given its poorer reliability, we acknowledge that our examination of associations involving this LPB factor was more exploratory in nature than those involving the highly-reliable IC/LPB factor, which were more likely to be robust to replication.

Direct and indirect pathways are now discussed for each model:

\section{- Step 1: Direct effects}

Model A: Emotional Problems. As shown in Fig. 1a, IC/LPB at age 13 was not directly associated with emotional problems at age 18; however, higher LPB was 
Fig. 1 Standardized path estimates for predictors of (a) emotional problems $(n=2,541)$; (b) physical health problems $(n=$ 2,534); and (c) NEET status ( $n=$ 3,077 ). All associations control for early adversity and childhood intelligence. Observed indicators for latent factors (circles) are not shown (see Fig. S1-S3 for underlying factor structures). Broken lines indicate nonsignificant associations (i.e., $p>.05) .{ }^{*} p<.05,{ }^{* *} p<.01$, $p<.001$ a

Age 13 Age 13-18

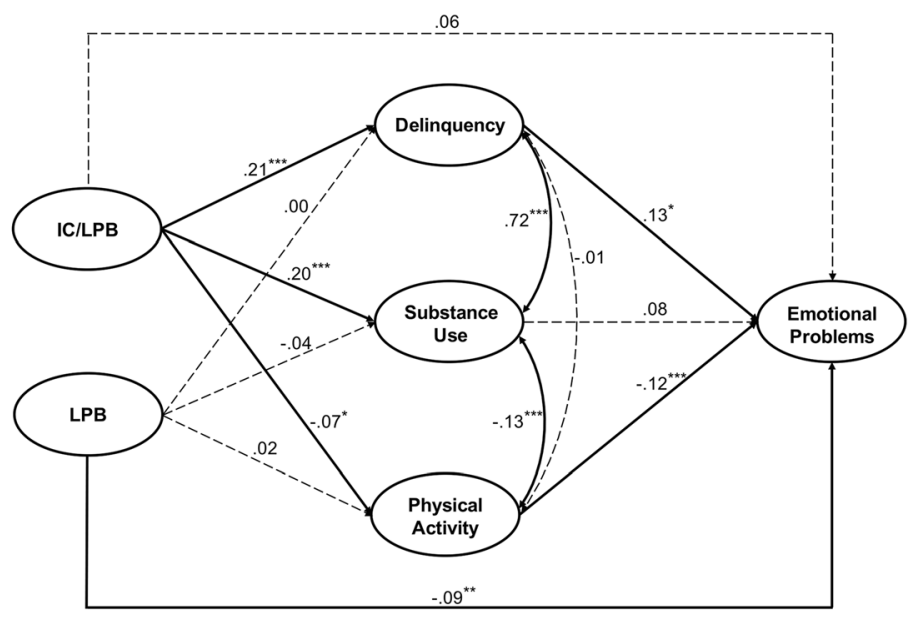

b Age 13 Age 13-18 Age 18

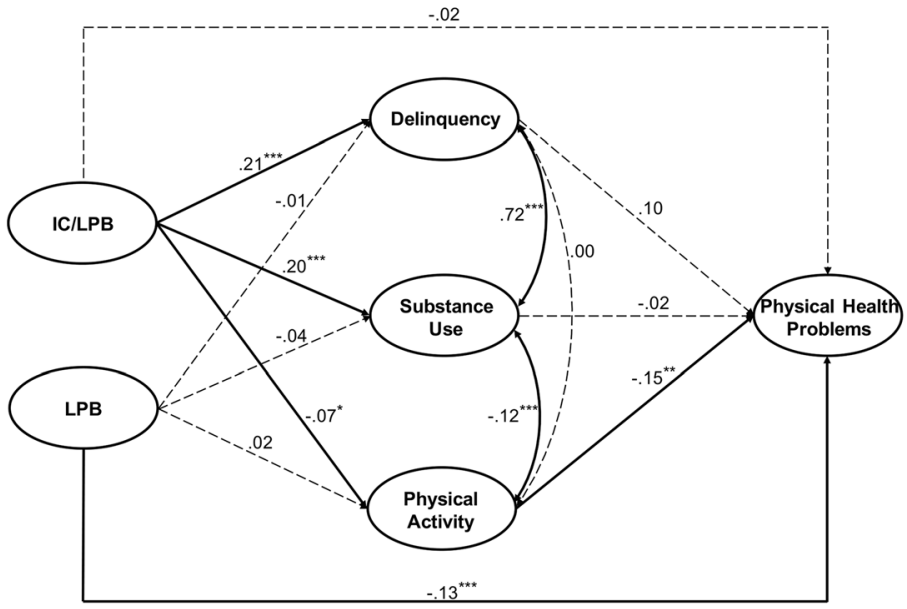

C

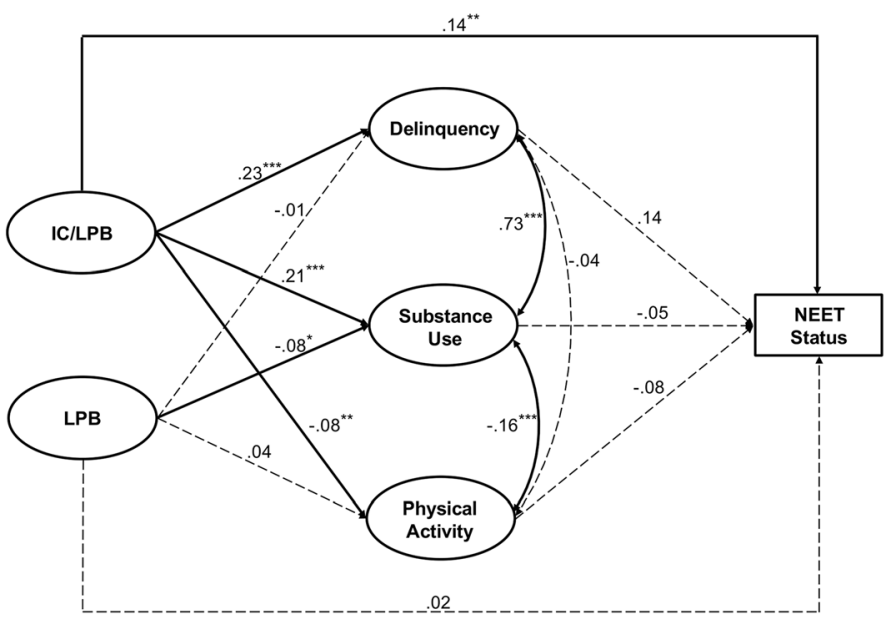


Table 1 Model fit information for estimated latent path models

\begin{tabular}{llllll}
\hline \multicolumn{7}{l}{ Model fit statistic } \\
\cline { 2 - 6 } & $\chi^{2}(d f)$ & $p$ value & CFI & TLI & RMSEA (90\% CIs) \\
\hline Model A (emotional problems) & $2,539.64(559)$ & $<.001$ & .92 & .91 & .037 (.036-.039) \\
Model B (physical health problems) & $3,520.67(744)$ & $<.001$ & .90 & .90 & $.038(.037-.040)$ \\
Model C (NEET status) & $2,137.90(345)$ & $<.001$ & .91 & .90 & $.041(.039-.043)$ \\
\hline
\end{tabular}

NEET not in education, employment, or training, $\chi^{2}$ chi-square statistic, CFI comparative fit Index, TLI TuckerLewis index (acceptable fit for both: $\geq .90$ ), RMSEA root mean square error of approximation (close fit: $\leq .05$ ), CIS confidence intervals

associated with lower levels of emotional difficulties $(b=$ $-.09, p=.006)$. In terms of intermediate direct effects, IC/ LPB was associated with higher levels of delinquency $(b=.21, p<.001)$ and substance use $(b=.20, p<.001)$, and lower levels of physical activity $(b=-.07, p=.023)$. The residual LPB factor did not significantly associate with any of the adolescent domains. Greater delinquency $(b=.13, p=.024)$ and lower physical activity $(b=-.12$, $p<.001)$ were, in turn, directly associated with greater emotional difficulties.

Model B: Physical Health Problems. Similar to Model A, although IC/LPB was not directly associated with physical health problems, higher LPB was directly associated with better physical health $(b=-.13, p<.001$; see Fig. 1b). However, associations between IC/LPB and LPB and adolescent domains (delinquency, substance use, and physical activity) produced the same pattern of effects, with broadly equivalent standardized estimates, as reported in Model A above. Finally, with regard to

Table 2 Bifactor-specific fit indices for general and specific factors at age 13 within each latent path model

\begin{tabular}{|c|c|c|c|c|}
\hline \multirow[t]{2}{*}{ Latent factor } & \multicolumn{4}{|c|}{ Bifactor-derived statistic } \\
\hline & $\omega_{H} / \omega_{H S}$ & $H$ & $\mathrm{ECV}$ & PUC \\
\hline \multicolumn{5}{|c|}{ Model A (emotional problems) } \\
\hline $\mathrm{IC} / \mathrm{LPB}$ & .716 & .824 & .708 & .545 \\
\hline IC & .049 & .262 & & \\
\hline LPB & .377 & .535 & & \\
\hline \multicolumn{5}{|c|}{ Model B (physical health problems) } \\
\hline $\mathrm{IC} / \mathrm{LPB}$ & .715 & .825 & .709 & .545 \\
\hline IC & .052 & .253 & & \\
\hline LPB & .377 & .535 & & \\
\hline \multicolumn{5}{|c|}{ Model C (NEET status) } \\
\hline $\mathrm{IC} / \mathrm{LPB}$ & .689 & .809 & .696 & .545 \\
\hline IC & .115 & .283 & & \\
\hline LPB & .352 & .518 & & \\
\hline
\end{tabular}

$\omega_{H}$ omega hierarchical (for IC/LPB), $\omega_{H S}$ omega hierarchical subscale (for IC and LPB), $H$ construct reliability, $E C V$ explained common variance, $P U C$ percentage uncontaminated correlations, NEET not in education, employment, or training these adolescent behaviors, lower levels of physical activity were related to higher levels of physical health difficulties $(b=-.15, p=.001)$. Neither delinquency nor substance use significantly predicted physical health.

Model C: NEET Status. Youth defined as NEET ( $n=$ $212 ; 6.9 \%)$ were coded 1 , with the remainder of the sample $(n=2,865 ; 93.1 \%)$ coded 0 . Therefore, a positive association suggested that higher levels of a given factor were associated with NEET classification at age 20. As seen in Fig. 1c, higher IC/LPB at age 13 was directly associated with NEET status $(b=.14, p=.001)$. No direct effect was observed for the LPB factor. Associations between IC/LPB and the adolescent variables were broadly similar to the previous two models, with one additional significant association: here, higher LPB was significantly related to lower substance $(b=-.08 ; p=.014)$. Finally, none of the three adolescent domains were significantly associated with NEET status.

\section{- Step 2: Mediation and indirect effects}

Significant indirect pathways are presented in Table 3. As no significant mediation was found, these pathways represent indirect effects (i.e., where the direct effect is non-significant). None of the bootstrapped $95 \%$ confidence intervals for these effects crossed zero. Full results of indirect effects analysis, including total effects, are available in Table S5.

Model A: Emotional Problems. One significant indirect effect was found: IC/LPB was associated with greater emotional problems via higher levels of adolescent delinquency $\left(b=.028, S E=.013, p=.034, P_{M}=.26\right)$.

Model B: Physical Health Problems. One indirect effect was observed in this model: IC/LPB was associated with greater physical health problems, via lower levels of physical activity $(b=.017, S E=.007, p=.009$, $P_{M}=1.13$ ). As direct and indirect effects had opposite signs, the estimate for the indirect effect was greater than that of the direct effect, resulting in a $P_{M}$ value $>1$. To provide an alternative measure of the size of this effect, this pathway accounted for $43.6 \%$ of the total indirect effect from IC/LPB to physical health issues. 
Table 3 Significant standardized indirect pathways for emotional problems and physical health problems

\begin{tabular}{|c|c|c|c|c|c|c|c|c|}
\hline \multirow[t]{2}{*}{ Age 13} & \multirow[t]{2}{*}{ Age $13-18$} & \multirow[t]{2}{*}{ Age 18} & \multirow[t]{2}{*}{ Estimate } & \multirow[t]{2}{*}{$S E$} & \multirow[t]{2}{*}{$p$ value } & \multicolumn{2}{|c|}{$95 \%$ bias-corrected CIs } & \multirow[t]{2}{*}{$P_{M}$} \\
\hline & & & & & & Lower & Upper & \\
\hline \multicolumn{9}{|l|}{ Model A } \\
\hline $\mathrm{IC} / \mathrm{LPB}[+]$ & Delinquency [+] & Emotional Problems [+] & .028 & .013 & .034 & .002 & .054 & .26 \\
\hline \multicolumn{9}{|l|}{ Model B } \\
\hline $\mathrm{IC} / \mathrm{LPB}[+]$ & Physical Activity [-] & Physical Health Problems [+] & .017 & .007 & .009 & .004 & .030 & $1.13^{\mathrm{a}}$ \\
\hline
\end{tabular}

$[+]=$ increasing; $[-]=$ decreasing; $\mathrm{CIs}=$ confidence intervals; $P_{M}=$ ratio of indirect effect to total effect. ${ }^{a} P_{M}$ is $>1$ due to opposite signs for the direct and indirect effect; this specific indirect effect represented $43.6 \%$ of the total indirect effect from IC/LPB to physical health problems

Model C: NEET Status. No significant indirect pathways were identified here.

\section{Discussion}

This study sought to evaluate the predictive utility of the shared and unique variances for IC and LPB on early-adult health and educational/occupational attainment, via direct and indirect developmental pathways. Four main findings are highlighted from these analyses.

First, having controlled for childhood adversity and cognitive function, the shared variance underlying these 11 items (i.e., IC/LPB), which accounted for the majority of total score variance, was indirectly associated with young-adult emotional difficulties via higher levels of adolescent delinquency. Longitudinal research has demonstrated the utility of adolescent callousness in predicting more delinquent and criminal outcomes in adulthood (e.g., McMahon et al. 2010; Kahn et al. 2013). Meanwhile, persistently high levels of youth conduct problem behaviors have themselves been shown to predict poorer adult mental health (e.g., Fergusson et al. 2005; Odgers et al. 2007). Therefore, these findings propose a developmental pathway through which these three domains may inter-relate over time; specifically, the severe and persistent pattern of antisocial behavior that characterizes high-callous youth (Frick et al. 2014) can be an adverse outcome in itself, and indirectly give rise to wider self-reported mental health difficulties in young adulthood.

Second, lower physical activity engendered an indirect effect between IC/LPB and physical health problems. Physical activity has established benefits on long-term health and well-being (Penedo and Dahn 2005; Reiner et al. 2013), and confers psychosocial resources that contribute to overall life success, most notably social support (Hogan et al. 2015; Mendonça et al. 2014). Participation in physical activity is strongly influenced by parental or peer support (Beets et al. 2010). At the same time, organized group activities (e.g., team sports) can themselves increase social support by providing more opportunities for social connectedness compared to individual healthrelated behaviors (Eime et al. 2013). Therefore, lower levels of physical activity at high levels of IC/LPB may also reflect poor social support. However, not all group activities are associated with positive adjustment: unstructured and unsupervised activities (e.g., hanging out with peers) generally increase the risk of delinquent or risky behaviors, compared to the protective effects conferred by participation in structured, organized, and adult-supervised activities (e.g., Hoeben and Weerman 2016; Osgood et al. 1996). Given that our measure simply assessed the average weekly frequency of any exercise, it was not possible to distinguish activity subtypes (i.e., independent vs teambased, structured vs unstructured), prohibiting formal examination of any additional mechanisms.

Third, IC/LPB was directly associated with nonparticipation in education, employment, or training at age 20. The proportion of NEET youth in our sample $(6.9 \%)$ was lower than the $14.9 \%$ rate reported for UK youth aged 16-24 at the time (April-June 2013; Office of National Statistics 2013). Of note, although IC/LPB was associated with greater delinquency and substance use, these behaviors were not predictive of NEET status, unlike previous longitudinal findings (Rodwell et al. 2017; Veldman et al. 2015). We suggest two reasons why our results differed from these studies. First, given that these adolescent variables were independently correlated with NEET status (see Table S4), it could be that prospective effects were accounted for by our controls here. Our adversity index included indicators of maternal education attainment and marital status, and we also controlled for IQ; all of these are robust independent risk factors for becoming NEET. In a similar way, Fergusson et al. (2005) found that an association between childhood CP and adverse adult psychosocial outcomes became non-significant once confounding factors, including family socio-economic disadvantage and IQ, were controlled for. Second, alternative developmental pathways not measured here may be more appropriate for poor academic or occupational success. For example, high-IC youth have been shown to perform worse on 
national standardized tests (Meehan et al. 2017). Academic failure, an established NEET risk factor, could therefore offer an indirect pathway from IC/LPB to NEET status by restricting later opportunities. In addition, it may be more pertinent to examine school-based behaviors (e.g., truancy, deviant peer affiliation, exclusion, teacher-child conflict), as school engagement and academic achievement are highly inter-related (Chase et al. 2014). As well as exerting unique effects, indicators of school disengagement may engender an indirect effect between delinquency or substance use and NEET status, as a more proximal measure of how these behaviors relate to later academic failure.

Finally, the specific LPB factor, or unique variance for low prosocial behavior beyond IC/LPB, was directly associated with fewer mental and physical health problems, suggesting a relatively well-adjusted developmental profile compared to the general factor. This unique variance for low prosocial behavior has previously been characterized by lower maternal warmth (Meehan et al. 2019). In line with consistent links between parental warmth and prosocial behaviors (Eisenberg et al. 2015), these youth may have less positive socialization, and hence be less considerate, due to the types of parenting behaviors to which they were exposed. Perhaps poor prosocial functioning limits interactions with peers, which, in turn, lowers the risk of affiliation with delinquent peers - delinquency, by and large, is believed to be (in part) a social behavior (Warr 2002). Consequently, they may not become involved in activities that compromise later health (e.g., delinquency, substance use). Elsewhere, while this LPB factor was previously related to greater social-cognitive deficits, these may reflect low-level difficulties within a normative community sample, rather than clinically-relevant impairments (i.e., autism diagnosis). These are speculative suggestions, however, as observed associations should be interpreted with caution given the factor's suboptimal bifactor fit indices. Moreover, as this LPB factor represents residualized variance, having partitioned out shared variance with IC, the extent to which the factor adequately reflects the original LPB construct is unclear, limiting meaningful interpretation of these effects. Incorporating further domains of functioning (e.g., bullying, friendship quality) may address uncertainty around the reliability of the LPB factor by offering a more nuanced picture of the behavioral profile associated with this residualized variance.

\section{Clinical Implications}

Overall, findings suggest that IC/LPB, which may represent a similar construct as previous empirically derived "callous-low prosocial' measures (Dadds et al. 2005; Viding et al. 2005), is also predictive of adverse health and social adjustment, in what is, to our knowledge, the first prospective study of these outcomes in relation to IC and LPB. By identifying indirect developmental pathways for IC/LPB, these results, in turn, highlight several targets for early clinical intervention that may mitigate the potential for long-term disadvantage among IC/LPB youth, even where levels of initial risk are high, as denoted by a more adverse early social context and poorer cognitive function.

First, efforts to reduce delinquency in adolescence may also promote better emotional well-being. High-callous youth, though not entirely unresponsive, have previously benefitted less from standard parent-training interventions aimed at reducing conduct problems compared to youth without these traits (Hawes et al. 2014). However, recent treatment efforts have devised more precise treatment targets for this subgroup of $\mathrm{CP}$ youth. Of note, greater reductions in $\mathrm{CP}$ have been reported for callous youth following interventions that include an emotion recognition training component (Dadds et al. 2012). School-based prevention training focused on increasing emotional awareness and social skills has also reported preliminary success in reducing symptoms of $\mathrm{CP}$ and callousness (Kyranides et al. 2017). Treatment designs that address these socio-affective skills may therefore reduce delinquent behaviors and, in turn, lessen overall risk for emotional difficulties into early adulthood. Adolescent levels of delinquency observed here are also likely to reflect continuity of these behaviors from childhood, as CP youth with elevated IC levels tend to show an earlier onset and more stable pattern of antisocial behavior (Frick et al. 2014). Consequently, preventive approaches are needed in early childhood, before the onset of severe problems, and when IC may be less likely to moderate intervention effects on problem behaviors (Hyde et al. 2013).

Second, promoting physical activity, or reducing sedentary and inactive behaviors, may improve long-term physical health, even among IC/LPB youth, who, based on these results, are more likely engage in risky or 'health-compromising' behaviors. Exercise-based interventions among school-aged children generally show a dose-response relationship with physical health: the more activity, the greater the health benefit (Janssen and LeBlanc 2010). Such interventions have also proven effective as adjuncts to mental health treatments (Josefsson et al. 2014; Stathopoulou et al. 2006; Rosenbaum et al. 2016). Despite evidence for a beneficial effect of these interventions on mental as well as physical health, no published study to date has examined exercise within treatment for callous traits. Given that youth high in callousness, irrespective of CP levels, report lower levels of self-esteem, social support and peer functioning (Fanti 2013; Haas et al. 2017), promoting group activity such as team sports may be particularly efficacious, due to the additional opportunities to increase social connectedness and improve social interaction skills.

\section{Strengths and Limitations}

The current study benefitted from a developmentallyinformed design, large sample sizes, and availability of 
repeated measures from multiple informants. Nonetheless, several limitations must be acknowledged. First, although data are longitudinal, conclusive casual effects cannot be established, as alternative models may offer equally plausible explanations for the data (Masten and Cicchetti 2010). In particular, unmeasured 'third-cause variables' may account for some effects; for example, shared genetic predispositions may underpin several of the measured domains, including IC and LPB themselves. Consequently, these models represent one of many possible configurations, and future work should assess the robustness of these effects by evaluating alternative solutions. Second, selection of time-points (e.g., IC) was based on the availability of data, rather than specific hypotheses about sensitive developmental periods. This limits conclusions that can be drawn regarding the role of timing, as effects and behaviors may have emerged earlier in development than their point of first measurement in ALSPAC. Repeated measures may help to specify critical periods of developmental vulnerability. Third, these models adopt a variable-based approach within a normative sample, comparing relative scores on continuous dimensions rather than categorical subgroups (e.g., classifying 'high-IC' or 'high-LPB' youth). It is unclear how findings might differ in high-risk samples, or at clinical cut-offs in the underlying distributions for IC or LPB. Fourth, our non-specific measure of physical activity did not differentiate between independent and group activities. More nuanced measures could clarify whether specific activities offer a greater promotive effect against adverse physical health. Fifth, although ALSPAC features a broad spectrum of socioeconomic backgrounds, the cohort includes relatively low rates of ethnic minorities, necessitating replication in more diverse samples. Finally, as discussed previously, attrition in ALSPAC has led to the loss of more vulnerable families at follow-up. However, Wolke et al. (2009) concluded that, although attrition affected overall prevalence rates for psychiatric disorder in ALSPAC, it did not attenuate relationships between risks and outcomes, provided that attrition bias was based around the risk factor rather than the outcome.

\section{Conclusions}

In summary, this study showed that, controlling for high childhood social disadvantage and low intelligence, the shared variance underlying IC and LPB in early adolescence was directly associated with young-adult non-participation in education and employment, and indirectly associated with adverse mental and physical health in young adulthood via delinquent and physically-active behaviors, respectively. Residual variance for LPB, in contrast, was related to better mental and physical health. These longitudinal models offer preliminary evidence for a number of developmental pathways through which IC/ LPB may exert enduring effects on general health and adjustment, and highlight two appropriate targets for multicomponent treatment efforts during adolescence, focused on both the reduction of delinquent or disruptive behaviors and promotion of physical activity.

Acknowledgments We are extremely grateful to all the families who took part in this study, the midwives for their help in recruiting them, and the whole ALSPAC team, which includes interviewers, computer and laboratory technicians, clerical workers, research scientists, volunteers, managers, receptionists, and nurses.

Funding The UK Medical Research Council (MRC) and Wellcome Trust (grant 102215/2/13/2) and University of Bristol provide core support for ALSPAC. This publication is the work of the authors and A.J.M. and E.D.B. will serve as guarantors for contents of this paper. A comprehensive list of grants funding is available on the ALSPAC website (http://www. bristol.ac.uk/alspac/external/documents/grant-acknowledgements.pdf). Collection of the specific measures utilized in this research was funded by the Wellcome Trust and MRC (grants 076467/Z/05/Z and 092731), the UKMRC (grant G0800612/86812), and the National Institutes of Health (grant MH087786-01). A.J.M. is supported by the Economic and Social Research Council (grant ES/J500057/1) and the National University of Ireland. Research reported in this publication was supported by awards from the National Institute of Child Health and Human Development (grant R01HD068437) and Economic and Social Research Council (grant ES/R005516/1) to E.D.B.

\section{Compliance with Ethical Standards}

Conflict of Interest Alan J. Meehan, Barbara Maughan, and Edward D. Barker declare that they have no conflicts of interest.

Experiment Participants As reported in the text, ethical approval for the original cohort study was obtained from the ALSPAC Ethics and Law Committee and Local Research Ethics Committees. All procedures performed in studies involving human participants were in accordance with the ethical standards of these institutional and national research committees, and with the 1964 Helsinki declaration and its later amendments or comparable ethical standards.

Informed Consent Informed consent was obtained from all individual participants included in the study.

Open Access This article is distributed under the terms of the Creative Commons Attribution 4.0 International License (http:// creativecommons.org/licenses/by/4.0/), which permits unrestricted use, distribution, and reproduction in any medium, provided you give appropriate credit to the original author(s) and the source, provide a link to the Creative Commons license, and indicate if changes were made.

\section{References}

Ahn, S., \& Fedewa, A. L. (2011). A meta-analysis of the relationship between children's physical activity and mental health. Journal of Pediatric Psychology, 36(4), 385-397. https://doi.org/10.1093/ jpepsy/jsq107.

American Psychiatric Association. (2013). Diagnostic and statistical manual of mental disorders: DSM-5 (5th ed.). Washington, DC: American Psychiatric Association. 
Barker, E. D., Oliver, B. R., Viding, E., Salekin, R. T., \& Maughan, B. (2011). The impact of prenatal maternal risk, fearless temperament and early parenting on adolescent callous-unemotional traits: a 14year longitudinal investigation. Journal of Child Psychology and Psychiatry, 52(8), 878-888. https://doi.org/10.1111/j.1469-7610. 2011.02397.x.

Beets, M. W., Cardinal, B. J., \& Alderman, B. L. (2010). Parental social support and the physical activity-related behaviors of youth: a review. Health Education \& Behavior, 37(5), 621-644. https://doi.org/ 10.1177/1090198110363884.

Bonifay, W., Lane, S. P., \& Reise, S. P. (2017). Three concerns with applying a bifactor model as a structure of psychopathology. Clinical Psychological Science, 5(1), 184-186. https://doi.org/10. $1177 / 2167702616657069$.

Bowen, E., Heron, J., Waylen, A., \& Wolke, D. (2005). Domestic violence risk during and after pregnancy: findings from a British longitudinal study. BJOG, 112(8), 1083-1089. https://doi.org/10.1111/ j.1471-0528.2005.00653.x.

Boyd, A., Golding, J., Macleod, J., Lawlor, D. A., Fraser, A., Henderson, J., Molloy, L., Ness, A., Ring, S., \& Davey Smith, G. (2013). Cohort profile: The 'children of the 90s' - the index offspring of the Avon longitudinal study of parents and children. International Journal of Epidemiology, 42(1), 111-127. https://doi.org/10.1093/ije/dys064.

Brown, T. A. (2006). Confirmatory factor analysis for applied research. New York: Guilford Press.

Browne, M. W., \& Cudeck, R. (1993). Alternative ways of assessing model fit. In K. A. Bollen \& J. S. Long (Eds.), Testing structural equation models (pp. 136-162). Newbury Park: Sage.

Byrd, A. L., Loeber, R., \& Pardini, D. A. (2012). Understanding desisting and persisting forms of delinquency: the unique contributions of disruptive behavior disorders and interpersonal callousness. Journal of Child Psychology and Psychiatry, 53(4), 371-380. https://doi.org/10.1111/j.1469-7610.2011.02504.x.

Byrd, A. L., Hawes, S. W., Loeber, R., \& Pardini, D. A. (2018). Interpersonal callousness from childhood to adolescence: developmental trajectories and early risk factors. Journal of Clinical Child \& Adolescent Psychology, 47(3), 467-482. https://doi.org/10.1080/ 15374416.2016.1144190.

Caprara, G. V., Barbaranelli, C., Pastorelli, C., Bandura, A., \& Zimbardo, P. G. (2000). Prosocial foundations of children's academic achievement. Psychological Science, 11(4), 302-306. https://doi.org/10. 1111/1467-9280.00260.

Caspi, A., Wright, B. R. E., Moffitt, T. E., \& Silva, P. A. (1998). Early failure in the labor market: childhood and adolescent predictors of unemployment in the transition to adulthood. American Sociological Review, 63(3), 424-451.

Chase, P. A., Hilliard, L. J., Geldhof, G. J., Warren, D. J., \& Lerner, R. M. (2014). Academic achievement in the high school years: the changing role of school engagement. Journal of Youth and Adolescence, 43(6), 884-896. https://doi.org/10.1007/s10964-013-0085-4.

Currie, J., \& Widom, C. S. (2010). Long-term consequences of child abuse and neglect on adult economic well-being. Child Maltreatment, 15(2), 111-120.

Dadds, M. R., Fraser, J., Frost, A., \& Hawes, D. J. (2005). Disentangling the underlying dimensions of psychopathy and conduct problems in childhood: a community study. Journal of Consulting and Clinical Psychology, 73(3), 400-410. https://doi.org/10.1037/0022-006X. 73.3.400.

Dadds, M. R., Perry, Y., Hawes, D. J., Merz, S., Riddell, A. C., Haines, D. J., Solak, E., \& Abeygunawardane, A. I. (2006). Attention to the eyes and fear-recognition deficits in child psychopathy. British Journal of Psychiatry, 189(3), 280-281. https://doi.org/10.1192/ bjp.bp. 105.018150 .

Dadds, M. R., Cauchi, A. J., Wimalaweera, S., Hawes, D. J., \& Brennan, J. (2012). Outcomes, moderators, and mediators of empathicemotion recognition training for complex conduct problems in childhood. Psychiatry Research, 199(3), 201-207. https://doi.org/ 10.1016/j.psychres.2012.04.033.

Der, G., Batty, G. D., \& Deary, I. J. (2009). The association between IQ in adolescence and a range of health outcomes at 40 in the 1979 US National Longitudinal Study of Youth. Intelligence, 37(6), 573-580.

Dube, S. R., Felitti, V. J., Dong, M., Chapman, D. P., Giles, W. H., \& Anda, R. F. (2003). Childhood abuse, neglect, and household dysfunction and the risk of illicit drug use: the adverse childhood experiences study. Pediatrics, 111(3), 564-572.

Eime, R. M., Young, J. A., Harvey, J. T., Charity, M. J., \& Payne, W. R. (2013). A systematic review of the psychological and social benefits of participation in sport for children and adolescents: informing development of a conceptual model of health through sport. International Journal of Behavioral Nutrition and Physical Activity, 10(98), 1-21. https://doi.org/10.1186/1479-5868-10-98.

Eisenberg, N., Fabes, R. A., \& Spinrad, T. L. (2006). Prosocial development. In N. Eisenberg \& W. Damon (Eds.), Handbook of child psychology: Vol. 3. Social, emotional, and personality development (6th ed., pp. 646-718). New York: Wiley.

Eisenberg, N., Spinrad, T. L., \& Knafo-Noam, A. (2015). Prosocial development. In J. E. Lamb \& R. M. Lerner (Eds.), Handbook of child psychology: Vol. 3. Social, emotional, and personality development (7th ed., pp. 610-656). New York: Wiley.

Fanti, K. A. (2013). Individual, social, and behavioral factors associated with co-occurring conduct problems and callous-unemotional traits. Journal of Abnormal Child Psychology, 41(5), 811-824. https://doi. org/10.1007/s10802-013-9726-z.

Felitti, V. J., Anda, R. F., Nordenberg, D., Williamson, D. F., Spitz, A. M., Edwards, V., et al. (1998). Relationship of childhood abuse and household dysfunction to many of the leading causes of death in adults: the adverse childhood experiences (ACE) study. American Journal of Preventive Medicine, 14(4), 245-258.

Fergusson, D. M., Horwood, J. L., \& Ridder, E. M. (2005). Show me the child at seven: the consequences of conduct problems in childhood for psychosocial functioning in adulthood. Journal of Child Psychology and Psychiatry, 46(8), 837-849. https://doi.org/10. 1111/j.1469-7610.2004.00387.x.

Flouri, E., \& Sarmadi, Z. (2016). Prosocial behavior and childhood trajectories of internalizing and externalizing problems: the role of neighborhood and school contexts. Developmental Psychology, 52(2), 253-258. https://doi.org/10.1037/dev0000076.

Flynn, E., Ehrenreich, S. E., Beron, K. J., \& Underwood, M. K. (2015). Prosocial behavior: Long-term trajectories and psychosocial outcomes. Social Development, 24(3), 462-482. https://doi.org/10. 1111/sode. 12100 .

Fontaine, N. M., McCrory, E. J., Boivin, M., Moffitt, T. E., \& Viding, E. (2011). Predictors and outcomes of joint trajectories of callousunemotional traits and conduct problems in childhood. Journal of Abnormal Psychology, 120(3), 730-742. https://doi.org/10.1037/ a0022620.

Forsman, M., Lichtenstein, P., Andershed, H., \& Larsson, H. (2010). A longitudinal twin study of the direction of effects between psychopathic personality and antisocial behaviour. Journal of Child Psychology and Psychiatry, 51(1), 39-47.

Franzén, E. M., \& Kassman, A. (2005). Longer-term labour-market consequences of economic inactivity during young adulthood: a Swedish national cohort study. Journal of Youth Studies, 8(4), 403-424.

Fraser, A., Macdonald-Wallis, C., Tilling, K., Boyd, A., Golding, J., \& Davey Smith, G. (2013). Cohort profile: the Avon longitudinal study of parents and children: ALSPAC mothers cohort. International Journal of Epidemiology, 42. https://doi.org/10.1093/ije/dys066.

Frick, P. J., \& Hare, R. D. (2001). The antisocial process screening device. Toronto: Multi-Health Systems.

Frick, P. J., O'Brien, B. S., Wootton, J. M., \& McBurnett, K. (1994). Psychopathy and conduct problems in children. Journal of 
Abnormal Psychology, 103(4), 700-707. https://doi.org/10.1037/ 0021-843X.103.4.700.

Frick, P. J., Bodin, S. D., \& Barry, C. T. (2000). Psychopathic traits and conduct problems in community and clinic-referred samples of children: further development of the psychopathy screening device. Psychological Assessment, 12(4), 382-393. https://doi.org/10. 1037/1040-3590.12.4.382.

Frick, P. J., Ray, J. V., Thornton, L. C., \& Kahn, R. E. (2014). Can callousunemotional traits enhance the understanding, diagnosis, and treatment of serious conduct problems in children and adolescents? A comprehensive review. Psychological Bulletin, 140(1), 1-57. https://doi.org/10.1037/a0033076.

Gerbino, M., Zuffiano, A., Eisenberg, N., Castellani, V., Luengo Kanacri, B. P., Pastorelli, C., et al. (2017). Adolescents' prosocial behavior predicts good grades beyond intelligence and personality traits. Journal of Personality, 86, 247-260. https://doi.org/10.1111/jopy.12309.

Goodman, R. (1997). The strengths and difficulties questionnaire: a research note. Journal of Child Psychology and Psychiatry, 38(5), 581-586. https://doi.org/10.1111/j.1469-7610.1997.tb01545.x.

Haas, S. M., Becker, S. P., Epstein, J. N., \& Frick, P. J. (2017). Callousunemotional traits are uniquely associated with poorer peer functioning in school-aged children. Journal of Abnormal Child Psychology, 46, 781-793. https://doi.org/10.1007/s10802-0170330-5.

Harpur, T. J., Hare, R. D., \& Hakstian, A. R. (1989). Two-factor conceptualization of psychopathy: construct validity and assessment implications. Psychological Assessment, 1(1), 6-17. https://doi.org/10. 1037/1040-3590.1.1.6.

Hawes, D. J., Price, M. J., \& Dadds, M. R. (2014). Callous-unemotional traits and the treatment of conduct problems in childhood and adolescence: a comprehensive review. Clinical Child and Family Psychology Review, 17(3), 248-267. https://doi.org/10.1007/ s10567-014-0167-1.

Hoeben, E. M., \& Weerman, F. M. (2016). Why is involvement in unstructured socializing related to adolescent delinquency? Criminology, 54(2), 242-281. https://doi.org/10.1111/1745-9125.12105.

Hogan, C. L., Catalino, L. I., Mata, J., \& Fredrickson, B. L. (2015). Beyond emotional benefits: physical activity and sedentary behaviour affect psychosocial resources through emotions. Psychology \& Health, 30(3), 354-369. https://doi.org/10.1080/08870446.2014. 973410.

Hu, L., \& Bentler, P. M. (1999). Cutoff criteria for fit indexes in covariance structure analysis: conventional criteria versus new alternatives. Structural Equation Modeling, 6(1), 1-55. https://doi.org/10. 1080/10705519909540118.

Hyde, L. W., Shaw, D. S., Gardner, F., Cheong, J., Dishion, T. J., \& Wilson, M. (2013). Dimensions of callousness in early childhood: links to problem behavior and family intervention effectiveness. Development and Psychopathology, 25(2), 347-363. https://doi. org/10.1017/S0954579412001101.

Janssen, I., \& LeBlanc, A. G. (2010). Systematic review of the health benefits of physical activity and fitness in school-aged children and youth. International Journal of Behavioral Nutrition and Physical Activity, 7(40), 1-16.

Josefsson, T., Lindwall, M., \& Archer, T. (2014). Physical exercise intervention in depressive disorders: meta-analysis and systematic review. Scandinavian Journal of Medicine \& Science in Sports, 24(2), 259-272. https://doi.org/10.1111/sms.12050.

Kahn, R. E., Byrd, A. L., \& Pardini, D. A. (2013). Callous-unemotional traits robustly predict future criminal offending in young men. Law and Human Behavior, 37(2), 87-97. https://doi.org/10.1037/ b0000003.

Kyranides, M. N., Fanti, K. A., Katsimicha, E., \& Georgiou, G. (2017). Preventing conduct disorder and callous unemotional traits: preliminary results of a school based pilot training program. Journal of
Abnormal Child Psychology, 46, 291-303. https://doi.org/10.1007/ s10802-017-0273-x.

Lynam, D. R., Miller, D. J., Vachon, D., Loeber, R., \& StouthamerLoeber, M. (2009). Psychopathy in adolescence predicts official reports of offending in adulthood. Youth Violence and Juvenile Justice, 7(3), 189-207. https://doi.org/10.1177/1541204009333797.

Masten, A. S., \& Cicchetti, D. (2010). Developmental cascades. Development and Psychopathology, 22(3), 491-495. https://doi. org/10.1017/S0954579410000222.

Mathieu, J. E., \& Taylor, S. R. (2006). Clarifying conditions and decision points for mediational type inferences in organizational behavior Journal of Organizational Behavior, 27(8), 1031-1056.

McMahon, R. J., Witkiewitz, K., \& Kotler, J. S. (2010). Predictive validity of callous-unemotional traits measured in early adolescence with respect to multiple antisocial outcomes. Journal of Abnormal Psychology, 119(4), 752-763. https://doi.org/10.1037/a0020796.

Meehan, A. J., Maughan, B., Cecil, C. A. M., \& Barker, E. D. (2017). Interpersonal callousness and co-occurring anxiety: developmental validity of an adolescent taxonomy. Journal of Abnormal Psychology, 126(2), 225-236. https://doi.org/10.1037/abn0000235.

Meehan, A. J., Hawes, D. J., Salekin, R. T., \& Barker, E. D. (2019). Shared and unique variances of interpersonal callousness and low prosocial behavior. Psychological Assessment, 31(3), 376-388. https://doi.org/10.1037/pas0000675.

Mendonça, G., Cheng, L. A., Mélo, E. N., \& de Farias, J. C. (2014). Physical activity and social support in adolescents: a systematic review. Health Education Research, 29(5), 822-839. https://doi. org/10.1093/her/cyu017.

Moffitt, T. E., Caspi, A., Harrington, H., \& Milne, B. J. (2002). Males on the life-course-persistent and adolescence-limited antisocial pathways: follow-up at age 26 years. Development and Psychopathology, 14(1), 179-207.

Moran, P., Ford, T., Butler, G., \& Goodman, R. (2008). Callous and unemotional traits in children and adolescents living in Great Britain. British Journal of Psychiatry, 192(1), 65-66. https://doi. org/10.1192/bjp.bp.106.034876.

Moran, P., Rowe, R., Flach, C., Briskman, J., Ford, T., Maughan, B., Scott, S., \& Goodman, R. (2009). Predictive value of callousunemotional traits in a large community sample. Journal of the American Academy of Child and Adolescent Psychiatry, 48(11), 1079-1084. https://doi.org/10.1097/CHI.0b013e3181b766ab.

Morris, R. G., \& Johnson, M. C. (2014). Sedentary activities, peer behavior, and delinquency among American youth. Crime \& Delinquency, 60(6), 939-968. https://doi.org/10.1177/0011128710386205.

Muthén, L. K., \& Muthén, B. O. (2012). Mplus user's guide: 1998-2012 (7th ed.). Los Angeles: Muthén \& Muthén.

Nantel-Vivier, A., Pihl, R. O., Côté, S., \& Tremblay, R. E. (2014). Developmental association of prosocial behaviour with aggression, anxiety and depression from infancy to preadolescence. Journal of Child Psychology and Psychiatry, 55(10), 1135-1144. https://doi. org/10.1111/jcpp. 12235 .

Odgers, C. L., Caspi, A., Broadbent, J. M., Dickson, N., Hancox, R. J., Harrington, H., Poulton, R., Sears, M. R., Thomson, W. M., \& Moffitt, T. E. (2007). Prediction of differential adult health burden by conduct problem subtypes in males. Archives of General Psychiatry, 64(4), 476-484.

Office of National Statistics (2013). Statistical Bulletin: Young people not in education, employment or training (NEET), November 2013. Retrieved June 5, 2019, from http://webarchive.nationalarchives. gov.uk/20160111051256/http://www.ons.gov.uk/ons/dep171778 337420.pdf .

Office of Population Censuses and Surveys. (1991). Standard occupational classification (Vol. Volume 3). London: HMSO.

Osgood, D. W., Wilson, J. K., O’Malley, P. M., Bachman, J. G., \& Johnston, L. D. (1996). Routine activities and individual deviant behavior. American Sociological Review, 61(4), 635-655. 
Pardini, D. A., \& Loeber, R. (2008). Interpersonal callousness trajectories across adolescence: early social influences and adult outcomes. Criminal Justice and Behavior, 35(2), 173-196. https://doi.org/10. 1177/0093854807310157.

Pardini, D. A., Obradovic, J., \& Loeber, R. (2006). Interpersonal callousness, hyperactivity/impulsivity, inattention, and conduct problems as precursors to delinquency persistence in boys: a comparison of three grade-based cohorts. Journal of Clinical Child and Adolescent Psychology, 35(1), 46-59. https://doi.org/10.1207/ s15374424jccp3501_5.

Penedo, F. J., \& Dahn, J. R. (2005). Exercise and well-being: a review of mental and physical health benefits associated with physical activity. Current Opinion in Psychiatry, 18(2), 189-193.

Preacher, K. J., Rucker, D. D., \& Hayes, A. F. (2007). Addressing moderated mediation hypotheses: theory, methods, and prescriptions. Multivariate Behavioral Research, 42(1), 185-227.

Raposa, E. B., Hammen, C. L., Brennan, P. A., O’Callaghan, F., \& Najman, J. M. (2014). Early adversity and health outcomes in young adulthood: the role of ongoing stress. Health Psychology, 33(5), 410-418. https://doi.org/10.1037/a0032752.

Reiner, M., Niermann, C., Jekauc, D., \& Woll, A. (2013). Long-term health benefits of physical activity - a systematic review of longitudinal studies. BMC Public Health, 13(813), 1-9. https://doi.org/10. 1186/1471-2458-13-813.

Reise, S. P., Bonifay, W. E., \& Haviland, M. G. (2013). Scoring and modeling psychological measures in the presence of multidimensionality. Journal of Personality Assessment, 95(2), 129-140. https://doi.org/10.1080/00223891.2012.725437.

Rodriguez, A., Reise, S. P., \& Haviland, M. G. (2016a). Applying bifactor statistical indices in the evaluation of psychological measures. Journal of Personality Assessment, 98(3), 223-237. https://doi.org/ 10.1080/00223891.2015.1089249.

Rodriguez, A., Reise, S. P., \& Haviland, M. G. (2016b). Evaluating bifactor models: calculating and interpreting statistical indices. Psychological Methods, 21(2), 137-150. https://doi.org/10.1037/ met0000045.

Rodwell, L., Romaniuk, H., Nilsen, W., Carlin, J., Lee, K., \& Patton, G. (2017). Adolescent mental health and behavioural predictors of being NEET: a prospective study of young adults not in employment, education, or training. Psychological Medicine, 48, 861-871. https://doi.org/10.1017/S0033291717002434.

Rosenbaum, S., Tiedemann, A., Stanton, R., Parker, A., Waterreus, A., Curtis, J., \& Ward, P. B. (2016). Implementing evidence-based physical activity interventions for people with mental illness: an Australian perspective. Australasian Psychiatry, 24(1), 49-54. https://doi.org/10.1177/1039856215590252.

Salekin, R. T. (2008). Psychopathy and recidivism from mid-adolescence to young adulthood: cumulating legal problems and limiting life opportunities. Journal of Abnormal Psychology, 117(2), 386-395. https://doi.org/10.1037/0021-843x.117.2.386.

Saunders, J. B., Aasland, O. G., Babor, T. F., De la Fuente, J. R., \& Grant, M. (1993). Development of the Alcohol Use Disorders Identification Test (AUDIT): WHO collaborative project on early detection of persons with harmful alcohol consumption-II. Addiction, 88(6), 791-804.

Skrondal, A., \& Rabe-Hesketh, S. (2004). Generalized latent variable modeling: Multilevel, longitudinal and structural equation models. Boca Raton: Chapman \& Hall/CRC.

Smith, D. J., \& McVie, S. (2003). Theory and method in the Edinburgh study of youth transitions and crime. British Journal of Criminology, 43(1), 169-195.
Spruit, A., Assink, M., van Vugt, E., van der Put, C., \& Stams, G. J. (2016). The effects of physical activity interventions on psychosocial outcomes in adolescents: a meta-analytic review. Clinical Psychology Review, 45, 56-71. https://doi.org/10.1016/j.cpr.2016.03.006.

Stathopoulou, G., Powers, M. B., Berry, A. C., Smits, J. A., \& Otto, M. W. (2006). Exercise interventions for mental health: a quantitative and qualitative review. Clinical Psychology: Science and Practice, 13(2), 179-193.

Taylor, S. E., Way, B. M., \& Seeman, T. E. (2011). Early adversity and adult health outcomes. Development and Psychopathology, 23(3), 939-954. https://doi.org/10.1017/S0954579411000411.

van Nieuwenhuijzen, M., Junger, M., Velderman, M. K., Wiefferink, K. H., Paulussen, T. W., Hox, J., et al. (2009). Clustering of healthcompromising behavior and delinquency in adolescents and adults in the Dutch population. Preventive Medicine, 48(6), 572-578. https://doi.org/10.1016/j.ypmed.2009.04.008.

Veldman, K., Reijneveld, S. A., Ortiz, J. A., Verhulst, F. C., \& Bültmann, U. (2015). Mental health trajectories from childhood to young adulthood affect the educational and employment status of young adults: results from the TRAILS study. Journal of Epidemiology \& Community Health, 69(6), 588-593. https://doi.org/10.1136/jech2014-204421.

Viding, E., Blair, R. J., Moffitt, T. E., \& Plomin, R. (2005). Evidence for substantial genetic risk for psychopathy in 7-year-olds. Journal of Child Psychology and Psychiatry, 46(6), 592-597. https://doi.org/ 10.1111/j.1469-7610.2004.00393.x.

Ware, J. E., Jr., \& Sherbourne, C. D. (1992). The MOS 36-item shortform health survey (SF-36): I. Conceptual framework and item selection. Medical Care, 30(6), 473-483.

Warr, M. (2002). Companions in crime: The social aspects of criminal conduct. New York: Cambridge University Press.

Watkins, M. W. (2013). Omega [computer software]. Phoenix: Ed \& Psych Associates.

Wechsler, D., Golombok, S., \& Rust, J. (1992). Manual for the Wechsler intelligence scale for children (3rd UK ed.). London: The Psychological Corporation.

Weinberg, N. Z., Rahdert, E., Colliver, J. D., \& Glantz, M. D. (1998). Adolescent substance abuse: a review of the past 10 years. Journal of the American Academy of Child \& Adolescent Psychiatry, 37(3), 252-261.

Wen, Z., \& Fan, X. (2015). Monotonicity of effect sizes: questioning kappa-squared as mediation effect size measure. Psychological Methods, 20(2), 193-203. https://doi.org/10.1037/met000002.

Wolke, D., Waylen, A., Samara, M., Steer, C., Goodman, R., Ford, T., \& Lamberts, K. (2009). Selective drop-out in longitudinal studies and non-biased prediction of behaviour disorders. British Journal of Psychiatry, 195(3), 249-256. https://doi.org/10.1192/bjp.bp.108. 053751.

Yu, C. Y. (2002). Evaluating cutoff criteria of model fit indices for latent variable models with binary and continuous outcomes. Doctoral dissertation, University of California, Los Angeles.

Publisher's Note Springer Nature remains neutral with regard to jurisdictional claims in published maps and institutional affiliations. 